\title{
The formation of disinfection by-products from the chlorination and chloramination of amides
}

\author{
Chrysoula Sfynia* \\ Department of Civil and Environmental Engineering, Imperial College London, \\ London, SW7 2AZ, UK \\ Water Science Institute, Cranfield University, Bedfordshire, MK43 0AL, UK \\ Tom Bond \\ Department of Civil and Environmental Engineering, University of Surrey, \\ Guildford, GU2 7XH, UK \\ Rakesh Kanda \\ Institute of Environment, Health and Societies, Brunel University London, \\ Uxbridge, UB8 3PH, UK \\ Michael R. Templeton \\ Department of Civil and Environmental Engineering, Imperial College London, \\ London, SW7 2AZ, UK
}




\section{Abstract}

2 This study examined the potential of six aliphatic and aromatic amides, commonly found in natural waters or used 3 as chemical aids in water treatment, to act as organic precursors for nine haloacetamides (HAcAms), five haloacetonitriles (HANs), regulated trihalomethanes (THMs) and haloacetic acids (HAAs) upon chlorination and

5 chloramination. The impact of key experimental conditions, representative of drinking water, including $\mathrm{pH}$ (7 \&

6 8), retention time ( $4 \& 24 \mathrm{~h})$ and bromide levels $(0 \& 100 \mu \mathrm{g} / \mathrm{L})$, on the generation of the target DBPs was 7 investigated. The highest aggregate DBP yields upon chlor(am)ination were reported for the the aromatic and 8 hydrophobic hydroxybenzamide; $2.7 \% \pm 0.1 \% \mathrm{M} / \mathrm{M}$ (chlorination) and 1.7\% M/M (chloramination). Increased 9 reactivity was observed in aliphatic and hydrophilic compounds, acrylamide $(2.5 \pm 0.2 \% \mathrm{M} / \mathrm{M})$ and acetamide $10(1.3 \pm 0.2 \% \mathrm{M} / \mathrm{M})$, in chlorination and chloramination, respectively. The addition of bromide increased average 11 DBP yields by 50-70\%. Relative to chlorination, the application of chloramines reduced DBP formation by $66.5 \%$ (without $\mathrm{Br}^{-}$) and by $46.4 \%$ (with $\mathrm{Br}^{-}$). However, bromine incorporation in HAAs and HAcAms was enhanced following chloramination, of concern due to the higher toxicological potency of brominated compounds.

15 Keywords: Disinfection by-products, Amide precursor, Chlor(am)ination, Bromine incorporation factor, 


\section{Introduction}

Natural water resources intended for human consumption are usually characterised by organic and inorganic constituents that stem from physicochemical, biological and anthropogenic activities. The disinfection of natural waters, variably enriched with these organic and inorganic constituents, referred as precursors, leads to the formation of disinfection by-products (DBPs), which have been the focus of a significant amount of investigation since the mid-1970s (Bellar et al., 1974; Rook, 1974). To-date, literature refers to more than 700 DBPs resulting from the most common disinfection methods (Han and Zhang, 2018; Krasner et al., 2006). Some of these DBPs are known or suspected to constitute risks to public health (Richardson et al., 2007; Plewa et al., 2008; Zhang et al., 2020) and are currently regulated, e.g. by the US Environmental Protection Agency (THMs: $80 \mu \mathrm{g} / \mathrm{L}$, HAAs: $60 \mu \mathrm{g} / \mathrm{L}$ ) and the European Union (THMs: $100 \mu \mathrm{g} / \mathrm{L}$ ), with water companies required to keep their concentrations as low as possible without compromising the effectiveness of disinfection (DWI, 2012).

To control the formation of regulated THMs and HAAs, some water utilities are switching from chlorination to chloramination, since it has been widely reported to minimise DBP formation in both real and artificial water matrices (Bougeard et al., 2010; Cowman and Singer, 1996; Parsons and Goslan, 2009). However, chloramination has also been associated with increased levels of nitrogenous DBPs (N-DBPs), namely N-nitrosodimethylamine (NDMA) (Mitch et al., 2009), cyanogen chloride (Krasner et al., 2012), and perhaps haloacetonitriles (HANs) and haloacetamides (HAcAms) (Huang et al., 2017), even studies on the formation of the latter two groups are conflicting (Mitch et al., 2009; Templeton et al., 2012). A recent study that included halonitrophenols, amongst other halogenated aromatic DBPs, highlighted the potential occurrence in drinking water and their significant in vitro toxicity (Zhang et al., 2020)

HAcAms were initially identified as DBPs in drinking water in the US N-DBP survey in 2000-2002 (Krasner et al., 2006; Weinberg et al., 2002). Although they occur in low concentrations, usually ten times lower than HAAs (Krasner et al., 2006), HAcAms are currently the focus of research, due to their reported potential risk of carcinogenicity and mutagenicity (Plewa et al., 2008; Richardson et al., 2007). According to Plewa et al. (2008), HAcAm are $142 \times$ and $12 \times$ more cytotoxic and genotoxic, 
respectively, than the five HAAs that are regulated in the US, and $2 \times$ more cytotoxic than the unregulated HANs. Limited information is available regarding HAcAm precursors and formation mechanisms, since it is a relatively new DBP group identified in drinking water. Several studies postulate that HAcAms are 'intermediate products' of HANs hydrolysis, which can further transform into the corresponding HAAs (Bond et al., 2014; Glezer et al., 1999; Reckhow et al., 2001). However, recently Huang et al. (2012) found that DCAcAm can be generated independently from DCAN during both chlorination and chloramination. That study suggested the need for investigating alternative pathways and potential nitrogenous and non-nitrogenous N-DBP precursors in drinking water during the application of chlor(am)ine (Chu et al., 2010a, 2010b; Kimura et al., 2013; Le Roux et al., 2016; Nihemaiti et al., 2016).

Interestingly, the DCAcAm yields reported from model precursor studies, that include amino acids, are significantly lower than those of DCAN (Chu et al., 2010b), whereas in studies that include real water matrices the levels of the two N-DBP groups are similar (mean: $1.4 \mu \mathrm{g} / \mathrm{L}$ and $1 \mu \mathrm{g} / \mathrm{L}$, respectively) (Krasner et al., 2006). The majority of reported HAcAm occurrence seems to be as a result of unknown precursors (Bond et al., 2012). The highest formation potential for DCAcAm has been linked to natural waters with significant hydrophilic acid fractions in the organic matter (Chu et al., 2010a), especially those characterised by protein-like structures. Several researchers have investigated the potential of these nitrogen-rich species, often associated with wastewater-impacted or algal-rich water matrices, such as amino acids (both aliphatic and aromatic), proteins, pyrroles, pyrimidines, lignin phenols to act as N-DBPs precursors by chlorinating and chloraminating model precursor compounds (Bond et al., 2014; Chu et al., 2010a; Chuang et al., 2015; Le Roux et al., 2016; Nihemaiti et al., 2016). Bond et al. (2014), assessed the effect of both chlorination and chloramination of seven model amine compounds at three $\mathrm{pH}$ values $(6,7$ and 8), and quantified the concentrations of DCAN, TCAN, chloroform and TCNM. Chu et al. ( 2010a) investigated the formation of DCAcAm from 20 amino acids during chlorination and chloramination, of which the most reactive was aspartic acid, followed by histidine with yields of 0.23 and $0.19 \% \mathrm{M} / \mathrm{M}$, respectively. Le Roux (2016) highlighted that the presence of aromatic moieties in the precursor pool, encourages the formation of N-DBPs during chloramination, in comparison with samples of high aliphatic content. In fact, the most reactive precursors were the 
non-nitrogenous compounds, resorcinol and phenol, that yielded, respectively, $1.14 \% \mathrm{M} / \mathrm{M}$ and $4.4 \%$ $\mathrm{M} / \mathrm{M}$ of DCAN, while $0.83 \% \mathrm{M} / \mathrm{M}$ and $0.22 \% \mathrm{M} / \mathrm{M}$ of DCAcAm, respectively, were also formed.

Amine-containing and amide-containing substances may be important N-DBP precursors, since they are abundant in natural surface water and sediments, represent a substantial fraction of dissolved organic nitrogen and around 2-3\% of total natural organic matter (Świetlik et al., 2004). Amides are also present in around $25 \%$ of pharmaceuticals and other medicinally important compounds (Ghose et al., 1999), which have been found in trace concentrations in the water cycle (Bull, 2014; WHO, 2011). In addition, it has been previously reported that their polarity and the presence of hydrogen atoms of the amide groups not only facilitate but also accelerate halogen substitution during oxidation (Yu and Reckhow, 2017).

The presence of bromide in water has been widely associated with elevated halogenated DBPs in both chlorinated and chloraminated systems (Baribeau et al., 2006; Chu et al., 2013; Cowman and Singer, 1996; Krasner et al., 2008), and increasing bromide levels results in changes in chlorine to bromine ratios and shifts speciation towards more brominated DBP species (Krasner et al., 2008; Symons et al., 1993); suspected to be of greater health significance than their chlorinated counterparts (Plewa et al., 2008). Therefore it is crucial to understand the role of bromine incorporation in both regulated and unregulated DBPs (Amy et al., 1991; Baribeau et al., 2006; Cowman and Singer, 1996; Symons et al., 1993). Hua and Reckhow (2012) calculated the bromine incorporation factor (BIF) for four DBP classes (THMs, di-HAAs, tri-HAAs and di-HANs) and postulated that these decreased with increasing contact time and temperature during both chlorination and chloramination. Even though $\mathrm{pH}$ had no effect in the bromine incorporation, the order of BIFs was di-HAN > THM \& di-HAA > tri-HAA upon chlorination, whereas upon chloramination HAAs exhibited higher BIF values. Otherwise however, there is little information on the role of bromide in the formation of N-DBPs, since the majority of model compound studies omit bromide spiking. An exception is the studies by Bond et al. $(2015,2009)$, that calculated BIF values and concluded that during chlorination of amines di-HAcAms present higher BIF than diHANs, whereas during chloramination, even though BIFs for di-HAcAms were lower than di-HANs BIF, both were significantly higher than from chlorination. 
Another important parameter is disinfectant contact time, since in occurrence studies with variable retention times, HAAs and HANs have been reported to increase overall with increasing contact time, between 2 and 100 hours, but with intermediate decreases between 24-72 hours (Bougeard et al., 2010; Chen and Weisel, 1998; Goslan et al., 2009; Koch et al., 1991; Templeton et al., 2012). Information about the fate of N-DBPs as a function of contact time, and especially for HAcAms is very limited, although, it is suggested that HAcAms (DCAcAm, DBAcAm, TCAcAm) levels may slightly increase in distribution (Bond et al., 2015).

Therefore, the objectives of this study were to compare the effects of chlor(am)ination under controlled laboratory conditions to examine the importance of variables such as bromide, contact time, $\mathrm{pH}$, precursor characteristics and disinfectant type, with a specific focus on amides and their role in all nine HAcAms formation, with simultaneous measurement of the formation of HANs, HAAs, and THMs. An improved understanding regarding the tendency of amides to form DBPs in drinking water will highlight their relative importance compared to other precursors and have implications for DBP minimisation strategies in water treatment practice.

\section{Materials and Methods}

All six selected amide model compounds were tested for the formation potential of 9 HAcAms, 5 HANs, and 9 HAAs during both chlorination and chloramination; at $\mathrm{pH} 7$ and 8, after 4 and 24 hours of contact, with the absence or presence of bromide $(100 \mu \mathrm{g} / \mathrm{L})$, representative of the typical conditions in drinking water treatment and distribution (Bond et al., 2015). THM yields, which were not the main focus of this study but were included for completeness, were quantified at 24 hours contact time at $\mathrm{pH} 7$ and 8 , both with and without bromide upon chlorination and chloramination.

\subsection{Selection of amides}

The selection of the amides was based on the following: their functional groups, structure, molar mass, hydrophilicity and previous reported DBP formation potential (Table 1). Acetamide has been previously reported as THM and HAA precursor (Bond et al., 2012, 2009), as well as of the following N-DBPs: DCAN, TCAN and TCNM (Bond et al., 2009). Acetoacetamide contains 
a beta-dicarbonyl group, which is known to act as a reactive THM and HAA precursor group (Dickenson et al., 2008). Polyacrylamide is a polymeric coagulant aid used in water treatment, however, despite approximately $95 \%$ of the polymers being absorbed in the floc during water treatment, a $5 \%$ remains dissolved in the water and may pass to the disinfection stage of treatment (Guzzo and Guezennec, 2015). Its susceptibility to multiple degradation pathways is high; the amide group can undergo hydrolysis or dehydration (Caulfield et al., 2003) that leads to the release of acrylamide. Acrylamide is a compound of health concern, readily mobile in aqueous environments and highly leachable in soil (WHO, 2004), with reported concentrations of $<5 \mu \mathrm{g} / \mathrm{L}$ in river and tap water samples in the US (WHO, 2004). Both acrylamide and polyacrylamide, apart from being used in water and wastewater treatment, are grouting agents in the construction of drinking water reservoirs and wells (IPCS and WHO, 1985). $\beta$-Alaninamide derives from the amino acid, $\beta$-alanine acid, known for generating significant yields of THMs and HANs (Hureiki et al., 1994). Hydroxybenzamide is an aromatic moiety and selected aromatic precursors have been previously shown to exhibit high N-DBP formation potentials (Le Roux et al., 2016).

This study included compounds ranging from slightly hydrophobic (log Kow <0.5) to highly hydrophilic $(\log$ Kow $=-1.8)$ (Table 1$)$. They were obtained at lab-grade purity or higher from SigmaAldrich (Darmstadt, Germany) and Finetech Industry (London, UK).

\subsection{Sample preparation}

For the sample preparation, each amide was added at $10 \mu \mathrm{M}$ and buffered at $\mathrm{pH} 7$ or 8 (10 mM sodium phosphate). Bromide was added at $100 \mu \mathrm{g} / \mathrm{L}$ for those samples which contained bromide. Next, either chlorine or chloramine (N/Cl molar ratio: 1.4/1) was added at a formation potential dose of $20 \mathrm{M} / \mathrm{M}$. Both chlorine $(0.25 \mathrm{M})$ and chloramine $(0.1 \mathrm{M})$ solutions, were measured by DPD-FAS titration in at least triplicate on the day of sample preparation (Apha et al., 1999). Sample bottles were then filled headspace-free before being left for 4 or 24 hours at room temperature. When the selected contact times were completed amide samples were quenched with $100 \mathrm{mg} / \mathrm{L}$ of ammonium chloride (chlorinated samples) and $50 \mathrm{mg} / \mathrm{L}$ of ascorbic acid (chloraminated samples), to preserve the individual analytes, and were extracted immediately (Domino et al., 2003; Liew et al., 2012; Munch and Hautman, 1995). 
Yu and Reckhow (2017) showed that the HAcAms (DCAcAm, BCAcAm and DBAcAm) identified todate using the most commonly employed analytical techniques are N-Cl-HAcAms; kinetic experiments indicated that HAcAms generated from chlorination are unstable and thus undergo instant $\mathrm{N}$ chlorination. The result is a hydrogen bond between the amino hydrogen and hypochlorite oxygen that leads to the formation of equal amount of N-Cl-HAcAms, highly stable in water, detected at the same retention time. In this study though, the use of quenching agents (ammonium chloride and ascorbic acid) was assumed to rapidly reduce the nitrogen-bound chlorine in the N-C-HAcAms back to simple HAcAms. All reagents used were of analytical purity or higher and all samples were prepared and extracted in duplicate.

\subsection{DBP Analyses}

The determination of all target DBPs in this study was performed by liquid-liquid extraction and gas chromatography - electron capture detector (GC-ECD) (Perkin Elmer Clarus 500), using two separate methods, a modified EPA Method 551.1 (for THMs, HANs and HAcAms) with a fused silica capillary column (RXi 5Sil MS, 30m· $0.25 \mathrm{~mm}$ ID, $0.25 \mu \mathrm{m}$ film thickness, Restek, USA) and added temperature increase rates up to $280^{\circ} \mathrm{C}$, and EPA Method 552.3 (for HAAs) (Domino et al., 2003; Munch and Hautman, 1995). The method detection limits of THMs, HAAs, HANs and HAcAms were respectively, 0.4, 0.5, 0.2 and $0.1 \mu \mathrm{g} / \mathrm{L}$. Approximately 240 samples were extracted and analysed for the four target DBP classes.

\subsection{Bromine incorporation factor (BIF)}

BIF is the ratio of the molar concentration of incorporated bromide into a given class of DBP divided by the total molar concentration of chlorine and bromine in that class (Hua and Reckhow, 2012). The degree of incorporation is a useful indicator to compare the degree of bromination of the DBP classes in the presence of chlor(am)ine, since brominated DBP species may be more genotoxic and carcinogenic than their chlorinated analogues (Richardson et al., 2007). The BIFs were calculated using Equations (1-5), where concentrations are on a molar basis, excluding HANs due to limited occurrence:

BIF (THMs) $=\frac{\left[\mathrm{CHBrCl}_{2}\right]+2 \cdot\left[\mathrm{CHBr}_{2} \mathrm{Cl}\right]+3 \cdot\left[\mathrm{CHBr}_{3}\right]}{\left[\mathrm{CHCl}_{3}\right]+\left[\mathrm{CHBrCl}_{2}\right]+\left[\mathrm{CHBr}_{2} \mathrm{Cl}\right]+\left[\mathrm{CHBr}_{3}\right]}$ Equation 1 
$\mathrm{BIF}($ tri-HAcAms $)=\frac{[\mathrm{BDCAcAm}]+2 \cdot[\mathrm{DBCAcAm}]+3 \cdot[\mathrm{TBAcAm}]}{[\mathrm{TCAcAm}]+[\mathrm{BDCAcAm}]+[\mathrm{DBCAcAm}]+[\mathrm{TBAcAm}]}$

Equation 5

The results of the above calculations were normalised by the number of halogens, i.e. di-halogenated and tri-halogenated compounds were divided by two and three, respectively. This normalisation produces BIF values between 0 (only chlorinated species presented) and 1 (only brominated species present).

\section{Results and Discussion}

\subsection{Formation of nitrogenous disinfection by-products (HAcAms and HANs)}

The direct chlor(am)ination of the selected amide precursors resulted in the detection of HAcAms under all experimental conditions (Fig.1 a-b), while HANs species were rarely detected, primarily at $24 \mathrm{~h}$ of retention time (Table 1). Generally, in the few samples that HANs were detected $(\mathrm{pH}$ 8), those yields were higher following chlorination and lower in chloramination than those of total HAcAm; with the exception of acetoacetamide. This pattern was in agreement with previous precursor studies of organic acids and natural organic matter solutions, that reported favouring of HAcAm formation via chloramination in the absence of bromide (Chu et al., 2016; Huang et al., 2017). In this study, of note, amide compounds at $\mathrm{pH} 7$ generated undetectable levels of HANs upon chlorination, whereas upon chloramination TCAN $(0.17 \% \mathrm{M} / \mathrm{M})$ was the only species at 24 hours in the $\beta$-alaninamide samples. Under the same conditions, the corresponding HAcAms species were present in the majority of the amide samples even at low contact time $(4 \mathrm{~h})$. The most abundant species was DCAcAm, ranging between $0.05-1.32 \% \mathrm{M} / \mathrm{M}$ and $0.01-0.08 \% \mathrm{M} / \mathrm{M}$, upon chlorination and chloramination, respectively. Unike at $\mathrm{pH} 7$, when the six amide precursors were chlorinated at $\mathrm{pH} 8$ both DCAN and TCAN levels were detected. This was only observedat 24 hours of retention time, however (Table 2). The above indicated that DCAcAm and TCAcAm yields were not solely due to the hydrolysis of DCAN and TCAN (Chu et al., 2010b; Reckhow et al., 2001) and that they could also have formed independently 
215 (Huang et al., 2012). In the absence of bromide, the most reactive amides for both chlorination and 216 chloramination were $\beta$-alaninamide $(1.32 \pm 0.09 \% \mathrm{M} / \mathrm{M})$ and acetoacetamide $(0.45 \pm 0.07 \% \mathrm{M} / \mathrm{M})$, after 217 both $\mathrm{pH} 7$ and 24 hours of retention time. Total HAcAm yields were reduced by $60-92 \%$ among the chloraminated amides, relative to the chlorinated ones. The molecular structure of the selected amides was considered an important formation factor. Acetoacetamide contains a $\beta$-dicarbonyl group, previously reported to be a reactive structural moiety with halogens (Dickenson et al., 2008), whereas $\beta$-alaninamide includes a beta carbon. At the same time, these amides were two of the most hydrophilic moieties $\left(\log K_{\text {ow }}\right)$ in this study (Table 1$)$, meaning that if they are present in water the likelihood to reach the disinfection stage of treatment is high, unless selective pre-treatment is in place (e.g granular activated carbon, biological filtration and advanced oxidation) (Bond et al., 2011). Polyacrylamide had a similar HAcAms formation in both $\mathrm{pH}$ and retention times, with mean yields of $0.064 \pm 0.003 \% \mathrm{M} / \mathrm{M}(\mathrm{pH} 7)$ and $0.051 \pm 0.008 \% \mathrm{M} / \mathrm{M}(\mathrm{pH} 8)($ Table 2). On the other hand, its monomer, acrylamide, formed undetectedyields of HAcAms at $\mathrm{pH}$ 7, whilst at $\mathrm{pH} 8$ HAcAm yields were significantly reduced after 24 hours (by 89\%). Recent studies confirm these findings for the above amide-based coagulants (Ding et al., 2018; Wang et al., 2018); polyacrylamide samples yielded 0.040\% $\mathrm{M} / \mathrm{M}$ of DCAcAm in chlorination and undetectable in chloramination, against $0.034 \% \mathrm{M} / \mathrm{M}$ and undetectable, respectively, in the current study. Similarly, with respect to acrylamide, DCAcAm were $0.11 \% \mathrm{M} / \mathrm{M}$ during chlorination and undetectable during chloramination, against $0.15 \% \mathrm{M} / \mathrm{M}$ and undetectable, respectively, in this study (Fig 1.b). Acetamide presented relatively low HAcAms yields, stable between the retention times $(0.09 \pm 0.0 \% \mathrm{M} / \mathrm{M})$ in $\mathrm{pH} 8$, and decreasing between 4 and 24 hours from $0.05 \pm 0.01 \% \mathrm{M} / \mathrm{M}$ to undetectable at $\mathrm{pH} 7$ upon chlorination (Fig. 1). The decrease was due to HAcAm hydrolysis and was related to a corresponding increase of HAAs during the same conditions (Fig. 1 a).

Decreasing but similar HAcAms yields at $\mathrm{pH} 7$ and $\mathrm{pH} 8$ were also observed for acetoacetamide, after 4 hours $(0.26 \%$ and $0.22 \%$, respectively) and 24 hours $(0.12 \%$ and $0.13 \%$, respectively). Interestingly, the aromatic nature of hydroxybenzamide did not favour HAcAm formation as much as expected during both chlorination and chloramination. Literature suggests that a ring-cleavage reaction is triggered when the aromatic ring is activated by the hydroxyl group, encouraging chlorine electrophilic substitution 
243 (Chu et al., 2010b; Hureiki et al., 1994; Nihemaiti et al., 2016). However, either chloramine cannot 244 trigger the rapid opening of the benzene ring (Chu et al., 2009) or the HAcAms previously formed at lowercontact times, regardless of their amount, were prone to hydrolyse at a faster rate. As such, hydroxybenzamide samples upon chlorination yielded $0.45 \pm 0.17 \% \mathrm{M} / \mathrm{M}(\mathrm{pH} 7)$ and $0.14 \pm 0.04 \%$ $\mathrm{M} / \mathrm{M}(\mathrm{pH} 8)$ of HAcAms after $4 \mathrm{~h}$, which then decreased to untectectable (pH 7) and $0.05 \% \mathrm{M} / \mathrm{M}(\mathrm{pH}$ 8) after $24 \mathrm{~h}$. On the other hand, upon chloramination hydroxybenzamide yielded $0.08 \% \mathrm{M} / \mathrm{M}(\mathrm{pH} 7)$ and $0.01 \% \mathrm{M} / \mathrm{M}(\mathrm{pH} 8)$ of HAcAms after $4 \mathrm{~h}$, which then decreased to $0.03 \% \mathrm{M} / \mathrm{M}(\mathrm{pH} 7)$ and remained the same in $\mathrm{pH} 8$ after $24 \mathrm{~h}$.

The average DCAcAm yields reported in the chloraminated amide samples $(0.06 \pm 0.01 \% \mathrm{M} / \mathrm{M})$ from the aliphatic precursors in this study (Fig. 1b) were similar to a previous study on aromatic nitrogenous amino acids ( $0.09 \pm 0.03 \% \mathrm{M} / \mathrm{M})$ (Le Roux et al., 2016), and higher than those reported in a study on low molecular weight non-nitrogenous organic acids (0.011\% M/M) (Chu et al., 2016).

Based on the experimental conditions used in this study, the presence of HANs was not necessarily expected (Clayden et al., 2001; Schreck, 1968). According to a recent publication (Wang et al., 2018), however, acrylamide can degrade during chlorination, via the Hoffman rearrangement, to form HANs and then HAcAms between 4 and 24 hours of contact time. In fact, this was not confirmed neither from the acrylamide nor from the other amide samples, since the general observation was that, with the exception of acetoacetamide, HAcAm yields peaked at 4 hours and then degraded at 24 hours during chlor(am)ination at both selected $\mathrm{pH}$ values. More specific, when acrylamide presented $0.12 \pm 0.02 \%$ M/M of HANs at 24 hours of retention time, HAcAms had decreased between 4 and 24 hours from 0.36 $\% \mathrm{M} / \mathrm{M}$ to $0.04 \% \mathrm{M} / \mathrm{M}$. Likewise, in the three cases that TCAN was the only species detected in chloramination, this is not associated with any simultaneous increase of TCAcAm or any other HAcAm species. Since there is not a known reaction pathway from an amide to form a haloacetonitrile, further investigation is needed to confirm whether any reagent used functioned as reducing agent.

\subsection{Formation of carbonaseous disinfection by-products (HAAs and THMs)}

The highest HAA yields were identified in the chlorinated samples at pH 7 (Fig.1a). Under these conditions hydroxybenzamide generated $1.05 \% \pm 0.2 \mathrm{M} / \mathrm{M}$ in 4 hours, followed by $\beta$-alaninamide and 
polyacrylamide samples that both generated $0.70 \% \pm 0.4 \mathrm{M} / \mathrm{M}$ after 24 hours. With the exception of the aromatic samples in $\mathrm{pH} 8$, it is noteworthy that the HAAs generated from aliphatic amide samples were statistically significant higher than the other DBP classes, representing 47-100 \% of the aggregate DBP yields during both chlorination and chloramination. When amide samples switched to chloramination, significantly lower amounts of total HAAs were generated, under all experimental conditions, with reductions ranging 42-75\%, already expected from literature (Bougeard et al., 2010; Goslan et al., 2009). The most reactive precursor became acetamide that generated $0.63 \% \pm 0.11 \% \mathrm{M} / \mathrm{M}$ at $\mathrm{pH} 8$ and 4 hours, followed by hydroxybenzamide that generated $0.53 \% \pm 0.09 \mathrm{M} / \mathrm{M}$ at $\mathrm{pH} 7$ and 24 hours, attributable to TCAA and MCAA yields, since DCAA was rarely identified above detection limits (Fig.3). This is possibly due to the low stability and faster degradation of TCAcAm to form TCAA in comparison with the mono and dichloro-compounds (Glezer et al., 1999). However, the absence of DCAA yields and the higher yields of TCAA than TCAcAm, designated that apart from HAcAms hydrolysis, chloramination favoured further halogenation of the supposed dihalogenated intermediate instead of oxidation or hydrolysis to form DCAA (Cowman and Singer, 1996). From a practical standpoint, it is highlighted that if the aliphatic and hydrophilic amides are still present in the water matrix prior disinfection, the regulated HAAs are likely to present the highest contribution in total DBPs pool of the treatment works, even with the absence of bromide.

Prior the addition of bromide, the most reactive precursor was $\beta$-alaninamide, which generated respectively $0.28 \pm 0.02 \% \mathrm{M} / \mathrm{M}$ and $0.0 .26 \pm 0.02 \% \mathrm{M} / \mathrm{M}$ of chloroform, upon chlorination and chloramination at 24 hours (Fig.1 a,b). In fact, upon chlorination, chloroform yields were observed above the detection limit only at $\mathrm{pH} 8$, whereas upon chloramination only at $\mathrm{pH} 7$ in $4 / 6$ amides. The formation selectivity between the two $\mathrm{pHs}$ and disinfection process are consistent with research on natural water and organic precursors (Bond et al., 2014; Diehl et al., 2000; Stevens et al., 1989). The electron donating group (Dickenson et al., 2008) present in $\beta$-alaninamide seemed to favour formation against all the other aliphatic precursors which in chloramination yielded $\leq 0.07 \% \mathrm{M} / \mathrm{M}$ (Fig. $1 \mathrm{~b}$ ). Previous studies using amines demonstrated that during chloramination chloroform generation was reduced by 66-93\% in comparison with the yields during chlorination (Bond et al., 2014). Chloroform 
formation in $24 \mathrm{~h}$ from acrylamide/ polyacrylamide was previously reported to be $0.07 / 0.15 \% \mathrm{M} / \mathrm{M}$ upon chlorination and 0.14/0.22 \% M/M upon chloramination, respectively (Ding et al., 2018); against 0.09/0.09 \% M/M in chlorination $(\mathrm{pH} 8)$ and $0.05 / 0.03 \% \mathrm{M} / \mathrm{M}$ in chloramination $(\mathrm{pH} 7)$ in this study. The differences are most likely due to the fivefold initial amide concentration and lower $\mathrm{pH}$ used in the earlier study (50 $\mu \mathrm{M}$ and $\mathrm{pH} 6$, rather than $10 \mu \mathrm{M})$. The presence of chloroform in varying degrees was explained by two mechanisms (Reckhow et al., 1990): either as a hydrolysis product of tri-HAAs, favoured by base-catalysed hydrolysis of the halogenated leaving group (Ding et al., 2018), or as an independent by-product of amide oxidation via a currently unknown pathway.

\subsection{Bromide addition in amide precursors}

The incorporation of bromide in the amide samples resulted in a significant increase in total HAcAms yield, for all the amides tested, without exception, in both chlorinated and chloraminated samples, with increases ranging between 35-98\%. It also shifted speciation towards DBAcAm and DBCAcAm (Fig.2). All chlorinated amides were evidently more reactive at $\mathrm{pH} 7$ during both retention times (Fig.2a), whilst chloraminated amides became more reactive at $\mathrm{pH} 8$ after a retention time of 24 hours (Fig.2b), due to the known increased selectivity of each disinfectant at the two-different $\mathrm{pH}$ of this study (Bowman and Mealy, 2007). Upon chloramination at $\mathrm{pH} 8$, total HAcAms concentrations were similar or higher than those upon chlorination. The most reactive precursor following chlorination became acetamide with $2.17 \pm 0.02 \% \mathrm{M} / \mathrm{M}$, closely followed by hydroxybenzamide that reached a peak of HAcAms yield of $2.08 \% \mathrm{M} / \mathrm{M}$ at 4 hours and acrylamide of $2.03 \% \mathrm{M} / \mathrm{M}$ in 24 hours, all at pH 7 (Fig.2a). In samples with polyacrylamide and acetoacetamide, a slight decrease (by median 8\%) of HAcAms yield with time was observed in $\mathrm{pH} 7$ but a significant increase was observed in $\mathrm{pH} 8$ (by median 48\%). On the other hand, $\beta$-alaninamide behaves in the opposite way; HAcAms yields were increasing in $\mathrm{pH}$ 7 (by 26\%) and decreasing in $\mathrm{pH} 8$ (by 36\%) with regards to retention time. During chloramination, HAcAms formation followed the same pattern in all the amide samples; In $\mathrm{pH}$ 7, yields decreased whereas in $\mathrm{pH} 8$ increased with time. During chloramination in brominated samples, the most reactive amides were acetamide ( $\mathrm{pH} 7-4 \mathrm{~h}$ ) and $\beta$-alaninamide ( $\mathrm{pH} 8-24 \mathrm{~h}$ ) yielding 0.81 and $0.80 \% \mathrm{M} / \mathrm{M}$, respectively (Fig.2b). It is noteworthy that when bromide was spiked at $\mathrm{pH}$ 7, HAcAm yields increased 
at least two-fold from those observed at $\mathrm{pH} \mathrm{8,} \mathrm{due} \mathrm{to} \mathrm{the} \mathrm{increased} \mathrm{stability} \mathrm{at} \mathrm{lower} \mathrm{pH}$ (Chu et al., 2016). Namely, acetamide samples under the same conditions generated $0.81 \%$ and $2.2 \% \mathrm{M} / \mathrm{M}$ upon chlorination, whereas generated $0.40 \%$ and $0.81 \% \mathrm{M} / \mathrm{M}$ upon chloramination, at $\mathrm{pH} 8$ and 7 respectively. Interestingly, at $\mathrm{pH} 7 \mathrm{HANs}$ species were not detected during chlorination even with the presence of bromide, however were detected during chloramination in low yields in four amide samples. The presence of bromide ion resulted in increased HAAs formation (10-80\%) during chlor(am)ination essentially at the low retention times (4 hours) and was characterised by a shift in speciation towards BCAA, DBAA and TBAA $(0.036 \% \pm 0.002 \mathrm{M} / \mathrm{M}, 0.042 \% \pm 0.009 \mathrm{M} / \mathrm{M}$ and $0.015 \% \pm 0.001 \mathrm{M} / \mathrm{M}$, respectively) (Fig.3 a,b). It is known that bromine-containing species, prominent after bromide spiking in this study, are more prone to degrade against the chlorine-containing (Baribeau et al., 2006; Zhou and $\mathrm{Xie}, 2002)$. Indeed, at 24 hours of retention time and $\mathrm{pH} 8$ it was observed that HAA yields were statistically lower or similar to those of 4 hours during both disinfection practices, due to the combining degradation; namely, polyacrylamide: $0.79 \% \pm 0.07 \mathrm{M} / \mathrm{M}(4 \mathrm{~h})-0.46 \% \pm 0.02 \mathrm{M} / \mathrm{M}(24 \mathrm{~h})$. On the other hand, in $\mathrm{pH} 7$, HAA yields generally increased significantly with time, except for acrylamide during chlorination and acetoacetamide samples during both disinfection practices. This trend may be associated with the dominance and degradation rate difference of the HAA species between the two pHs and/or the simultaneous conversion of HAcAms to HAAs under the same conditions (Ding et al., 2018). Even though the last assumption may explain the HAAs increases with time in the chloraminated samples of $\mathrm{pH} 7$, it cannot function as an explanation for the chlorinated ones where the corresponding HAcAms species presented resistance in degradation. This indicated that amides may also function as independent precursors for HAAs via alternative pathways. The most reactive amides were acetoacetamide $(0.67 \% \pm 0.08 \% \mathrm{M} / \mathrm{M})$ and acetamide $(0.57 \% \pm 0.10 \% \mathrm{M} / \mathrm{M})$, in chlorination and chloramination, respectively. Following bromide spiking, total THM yields increased by $36-85 \%$ upon chlor(am)ination, and yields were finally identified at both $\mathrm{pH}$ values, with the most abundant species being BDCM and DBCM (Fig.4 a,b). The most reactive precursor became the aromatic hydroxybenzamide, which generated $0.91 \pm 0.05 \% \mathrm{M} / \mathrm{M}$ and $0.57 \pm 0.09 \% \mathrm{M} / \mathrm{M}$ of THMs, in chlorination and chloramination, respectively. 
In chlorinated amide samples, the BIF calculations indicated that the amount of bromine incorporation in di-HAcAms $(0.7 \pm 0.1)$ was significantly higher than that of di-HAAs $(0.4 \pm 0.1)$. However, bromine incorporation in di-HAcAms remained similar or increased with contact time by $15 \%$, with that being more significant for di-HAAs, since bromine-containing DBPs form slower than the chlorinated. Likewise in chloraminated samples, BIFs were $0.8 \pm 0.1$ and $0.6 \pm 0.1$ in di-HAcAms and di-HAAs, respectively, with a tendency to increase between 4 and 24 hours, by averages of $25 \%$ and $41 \%$, with the exception of di-HAAs in acetoacetamide and acrylamide. The different levels of incorporation in those two classes suggest a potential alternative pathway to the formation of HAAs from the model amides, rather than hydrolysis of HAcAm alone. Unlike the di- species, incorporation of bromine in triHAcAms (0.7) was lower than that of tri-HAAs $(0.9 \pm 0.1)$, under the same conditions upon chlor(am)ination. It has to be noted that this trend was observed due to the limited detection of TCAA in amide samples, the only exclusive chlorine-containing tri-HAA. The BIFs of THMs were generally significantly lower than those of HAAs and HAcAms, and decreased between chlorinated and chloraminated amide samples, from 0.4 to 0.1 , respectively. A recent study, though, reported that BIFs of THMs were higher than those of HAcAms in chloramination (Huang et al., 2017); this deviation is mainly due to the inclusion of four HAcAms species against all nine in this study. Since similar patterns (and similar percentages) with contact time were observed during both disinfection processes, the effect of disinfectant was found to be of secondary importance, and bromine reactions were more dependent on contact time and precursor characteristics. The order of mean BIFs upon chlor(am)ination of the selected DBPs groups in the amide samples quantified; was tri-HAAs > di-HAcAms > tri-HAcAms > di-HAAs $\geq$ THMs, in agreement with bromine incorporation in amines (Bond et al., 2015). In agreement with previous literature, with the exception of THMs, BIF values in chloraminated samples for HAAs and HAcAms, were generally slightly higher than in chlorinated samples (Bond et al., 2015). This trend was most prominent for di-HAAs, from the highly reactive acetoacetamide and hydroxybenzamide, where mean BIFs were respectively $65 \%$ and $26 \%$ higher in chloraminated than in chlorinated samples. Even though chloramination reduced DBP yields in absolute terms, it enhanced bromide incorporation into classes such as HAAs and HAcAms, and switches speciation towards more brominated species, suspected of being of greater health significance. 


\subsection{Aggregate DBP formation}

382

The aggregate DBP yields (i.e. the sum of all individual precursor yields) of HAcAms, HANs, HAAs and THMs, which varied significantly between the disinfectants and the presence/absence of bromide. This revealed some important trends for drinking water treatment; Relative to chlorination, the median aggregate formation was reduced by respectively $66.5 \%$ and $50.9 \%$ across the two $\mathrm{pH}$ levels ( 8 and 7 ) without the presence of bromide, and by $46.4 \%$ and $45.5 \%$ with the presence of bromide, by instead applying pre-formed chloramines. The formation of total HAcAms dramatically decreased with increasing $\mathrm{pH}$ during both chlorination and chloramination, however the formation of the other DBP classes was relatively insensitive to $\mathrm{pH}$ alteration. As expected, the presence of bromide levels resulted in significant increases of the selected DBPs in $\mathrm{pH} 7$ by $70 \%$ and $64 \%$, during chlorination and chloramination, respectively, whereas in $\mathrm{pH} 8$ these increases were $50 \%$ and $72 \%$. The most reactive amide precursor in chlorinated samples was hydroxybenzamide $(2.7 \% \pm 0.1 \mathrm{M} / \mathrm{M})$ followed by acrylamide $(2.5 \% \pm 0.2 \mathrm{M} / \mathrm{M})$ at $\mathrm{pH} 7$ and $\beta$-alaninamide $(2.1 \% \pm 0.2 \mathrm{M} / \mathrm{M})$ at $\mathrm{pH} 8$, whereas in chloraminated samples the most reactive amides was hydroxybenzamide $(1.7 \% \mathrm{M} / \mathrm{M})$ and acetamide $(1.3 \pm 0.3 \mathrm{M} / \mathrm{M})$ at $\mathrm{pH}$ 7. Aggregate yields were primarily attributable to HAcAms and HAAs generation, and to a lesser extent to HANs and THMs. This highlighted that the main formation mechanism for HAcAms was the oxidation of amide structures; the alpha carbon of amide group was substituted by halogens, followed by the cleavage between alpha and beta carbon. Overall, the aromatic and hydrophobic moiety functioned as the most significant THM precursor, rather than HAAs and HAcAms, for which aliphatic and hydrophilic amides were more significant. This suggested that if water utilities consider enhanced precursor removal as an operational strategy for DBP control, the success in minimising the individual classes may differ based on the success in removing their individual precursors.

\section{Conclusions}


407 for various DBPs upon chlorination and chloramination, under a range of water quality conditions 408 (bromide presence/absence, $\mathrm{pH}$ and contact time).

- The direct chlor(am)ination of the six amide precursors generated HAcAms, HANs, HAAs and THMs yields in varying degrees, with maximum yields being respectively, 2.2, 0.2, 1 and $0.9 \%$ M/M.

- The presence of bromide resulted in significant increases in DBP formation respectively, by $50 \%$ and $72 \%$, in chlorination and chloramination.

- The implementation of chloramines resulted in significant decreases in average THM, HAA, and HAcAm yields by of $95 \%, 63 \%$ and $58 \%$, respectively.

- Even though chloramination reduces DBP yields (absolute terms), it enhances bromide incorporation into HAAs and HAcAms, and favours speciation towards more brominated species which are suspected of being of greater health significance.

- HAcAm generation was not solely related to hydrolysis of HANs, and they were demonstrated to form independently.

- The aliphatic amides functioned as important precursors for HAcAms and HAAs, whereas the aromatic hydroxybenzamide was more significant for THMs.

\section{References}

Amy, G.L., Tan, L., Davis, M.K., 1991. The effects of ozonation and activated carbon adsorption on trihalomethane speciation. Water Res. 25, 191-202.

Apha, Water Environment Federation, American Water Works Association, 1999. Standard Methods for the Examination of Water and Wastewater, 20th ed, Standard Methods for the Examination of Water and Wastewater. Washington DC.

Baribeau, H., Boulos, L., Haileselassie, H., Crozes, G., Singer, P.C., Nichols, C., Schlesinger, S.A., Gullick, R.W., Williams, S.L., Williams, R.L., Fountleroy, L., Andrews, S.A., Moffat, E., 2006. Formation and decay of disinfection by-products in the distribution system. AWWA Res. Found. 1-360.

Bellar, T.A., Lichtenberg, J.J., Kroner, R.C., 1974. The occurence of organohalides in chlorinated drinking waters. J. Am. Water Work. Assoc. 66, 703-706.

Bond, T., Goslan, E.H., Parsons, S.A., Jefferson, B., 2011. Treatment of disinfection by-product precursors. Environ. Technol. $32,1-25$.

Bond, T., Goslan, E.H., Parsons, S.A., Jefferson, B., 2009. Disinfection byproduct formation and fractionation behavior of natural organic matter surrogates. Environ. Sci. Technol. 43, 5982-5989.

Bond, T., Mokhtar Kamal, N.H., Bonnisseau, T., Templeton, M.R., 2014. Disinfection by-product formation from the chlorination and chloramination of amines. J. Hazard. Mater. 278, 288-296.

Bond, T., Templeton, M.R., Graham, N., 2012. Precursors of nitrogenous disinfection by-products in drinking water--A critical review and analysis. J. Hazard. Mater. 235-236, 1-16.

Bond, T., Templeton, M.R., Mokhtar Kamal, N.H., Graham, N., Kanda, R., 2015. Nitrogenous disinfection byproducts in English drinking water supply systems: Occurrence, bromine substitution and correlation analysis. Water Res. 85, 85- 
94.

Bougeard, C.M., Goslan, E.H., Jefferson, B., Parsons, S.A., 2010. Comparison of the disinfection by-product formation potential of treated waters exposed to chlorine and monochloramine. Water Res. 44, 729-40.

Bowman, G., Mealy, R., 2007. The Fundamentals of Chlorine Chemistry and Disinfection.

Bull, S., 2014. Toxicological evaluation for pharmaceuticals in drinking water - Final report. Drink. Water Insp.

Caulfield, M.J., Hao, X., Qiao, G.G., Solomon, D.H., 2003. Degradation on polyacrylamides. Part I. Linear polyacrylamide. Polymer (Guildf). 44, 1331-1337.

Chen, W.J., Weisel, C.P., 1998. Halogenated DBPs concentrations in a distribution system. J. Am. Water Work. Assoc. 90, $151-163$.

Chu, W.-H., Gao, N.-Y., Zhao, S.-J., Deng, H.-P., 2009. The mechanism analysis of formation of chloroform during typical dissolved organic nitrogen tyrosine chlorination in drinking water. Acta Chim. Sin. 67, 2505-2510.

Chu, W., Gao, N., Deng, Y., 2010a. Formation of haloacetamides during chlorination of dissolved organic nitrogen aspartic acid. J. Hazard. Mater. 173, 82-86.

Chu, W., Gao, N., Deng, Y., Krasner, S.W., 2010b. Precursors of dichloroacetamide, an emerging nitrogenous DBP formed during chlorination or chloramination. Environ. Sci. Technol. 44, 3908-3912. https://doi.org/10.1021/es100397x

Chu, W., Gao, N., Yin, D., Krasner, S.W., 2013. Formation and speciation of nine haloacetamides, an emerging class of nitrogenous DBPs, during chlorination or chloramination. J. Hazard. Mater. 260, 806-12.

Chu, W., Li, X., Bond, T., Gao, N., Yin, D., 2016. The formation of haloacetamides and other disinfection by-products from non-nitrogenous low-molecular weight organic acids during chloramination. Chem. Eng. J. 285, 164-171.

Chuang, Y.H., McCurry, D.L., Tung, H.H., Mitch, W.A., 2015. Formation pathways and trade-offs between haloacetamides and haloacetaldehydes during combined chlorination and chloramination of lignin phenols and natural waters. Environ. Sci. Technol. 49, 14432-14440.

Clayden, J., Greeves, N., Warren, S., Wothers, P., 2001. Organic Chemistry. Am. Nat. 40, 1990-1992.

Cowman, G.A., Singer, P.C., 1996. Effect of bromide ion on haloacetic acid speciation resulting from chlorination and chloramination of aquatic humic substances. Environ. Sci. Technol. 30, 16-24.

Dickenson, E.R. V., Summers, S.R., Croué, J.-P., Gallard, H., 2008. Haloacetic acid and trihalomethane formation from the chlorination and bromination of aliphatic $\beta$-Dicarbonyl acid model compounds. Environ. Sci. Technol. 42, 3226-3233.

Diehl, A.C., Gerald, S.E., Symons, J.M., Krasner, S.W., Hwang, C.J., Barrett, S.E., 2000. DBPs during Chloramination. J. Am. Water Work. Assoc. 92, 76-90.

Ding, S., Chu, W., Bond, T., Cao, Z., Xu, B., Gao, N., 2018. Contribution of amide-based coagulant polyacrylamide as precursors of haloacetamides and other disinfection by-products. Chem. Eng. J. 350, 356-363.

Domino, M.M., Pepich, B. V., Munch, D.J., Fair, P.S., Xie, Y., Munch, J.W., Hodgeson, J.W., 2003. Method 552.3: Determination of Haloacetic Acids and Dalapon in Drinking Water by Liquid-Liquid Microextraction, Derivatization, and Gas Chromatography with Electron Capture Detection. US Environ. Prot. Agency 1-55.

DWI, 2012. Guidance on the implementation of the water supply (water quality) regulations 2000 (as amended) in England. Drink. Water Insp. 98.

Ghose, A.K., Vellarkad, V.N., Wendoloski, J.J., 1999. A Knowledge-Based Approach in Designing Combinatorial or Medicinal Chemistry Libraries for Drug Discovery. 1. A Qualitative and Quantitative Characterization of Known Drug Databases. J. Comb. Chem. 1, pp 55-68.

Glezer, V., Harris, B., Tal, N., Iosefzon, B., Lev, O., 1999. Hydrolysis of haloacetonitriles: Linear free energy relationship, kinetics and products. Water Res. 33, 1938-1948.

Goslan, E.H., Krasner, S.W., Bower, M., Rocks, S.A., Holmes, P., Levy, L.S., Parsons, S.A., 2009. A comparison of disinfection by-products found in chlorinated and chloraminated drinking waters in Scotland. Water Res. 43, 46984706.

Guzzo, J., Guezennec, A.-G., 2015. Degradation and transfer of polyacrylamide based flocculent in sludge and industrial and natural waters. Environ. Sci. Pollut. Res. 22, 6387-6389.

Han, J., Zhang, X., 2018. Evaluating the Comparative Toxicity of DBP Mixtures from Different Disinfection Scenarios: A New Approach by Combining Freeze-Drying or Rotoevaporation with a Marine Polychaete Bioassay. Environ. Sci. Technol. 52, 10552-10561.

Hua, G., Reckhow, D.A., 2012. Evaluation of bromine substitution factors of DBPs during chlorination and chloramination. Water Res. 46, 4208-4216.

Huang, H., Chen, B.Y., Zhu, Z.R., 2017. Formation and speciation of haloacetamides and haloacetonitriles for chlorination, chloramination, and chlorination followed by chloramination. Chemosphere 166, 126-134.

Huang, H., Wu, Q.Y., Hu, H.Y., Mitch, W.A., 2012. Dichloroacetonitrile and dichloroacetamide can form independently during chlorination and chloramination of drinking waters, model organic matters, and wastewater effluents. Environ. Sci. Technol. 46, 10624-10631.

Hureiki, L., Croué, J.-P., Legube, B., 1994. Chlorination studies of free and combined amino acids. Water Res. 28, 25212531.

IPCS, WHO, 1985. Acrylamide International Programme on Chemical Safety (Environmental Health Criteria 49). Geneva.

Kimura, S.Y., Komaki, Y., Plewa, M.J., Mariñas, B.J., 2013. Chloroacetonitrile and N,2-dichloroacetamide formation from the reaction of chloroacetaldehyde and monochloramine in water. Environ. Sci. Technol. 47, 12382-12390.

Koch, B., Kramer, S.W., Schimpf, W.K., Sclimenti, M.J., 1991. Predicting the formation of DBPs by the simulated distribution system. Am. Water Work. Assoc. 83, 62-70.

Krasner, S.W., Lee, C.F.T., Chinn, R., Hartono, S., Weinberg, H.S., Richardson, S.D., Pressman, J., Speth, T.F., Miltner, R., Simmons, J.E., 2008. Bromine incorporation in regulated and emerging DBPs and the relative predominance of mono, di-, and trihalogenated DBPs. Proc. AWWA WQTC. Denver, Color. AWWA 1-16.

Krasner, S.W., Mitch, W.A., Westerhoff, P., Dotson, A., 2012. Formation and control of emerging C- and N-DBPs in drinking 
water. J. Am. Water Work. Assoc. 104, 582-595.

Krasner, S.W., Weinberg, H.S., Richardson, S.D., Pastor, S.J., Chinn, R., Sclimenti, M.J., Onstad, G.D., Thruston, A.D., 2006. Occurrence of a new generation of disinfection byproducts. Environ. Sci. Technol. 40, 7175-7185.

Le Roux, J., Nihemaiti, M., Croué, J.P., 2016. The role of aromatic precursors in the formation of haloacetamides by chloramination of dissolved organic matter. Water Res. 88, 371-379.

Liew, D., Linge, K.L., Joll, C.A., Heitz, A., Charrois, J.W.A., 2012. Determination of halonitromethanes and haloacetamides: an evaluation of sample preservation and analyte stability in drinking water. J. Chromatogr. A 1241, 117-22.

Mitch, W.A., Krasner, S.W., Paul, W., Dotson, A., 2009. Occurrence and Formation of Nitrogenous Disinfection By-Products, Water Research Foundation \& US Environmental Protection Agency. Washington, D.C.

Munch, D.J., Hautman, D.P., 1995. Method 551.1: Determination of chlorination disinfection byproducts, chlorinated solvents , and halogenated pesticides/ herbicides in drinking water by liquid-liquid extraction and gas chromatography with electron-capture detection. US Environ. Prot. Agency 1-61.

Nihemaiti, M., Le Roux, J., Hoppe-Jones, C., Reckhow, D.A., Croué, J.-P., 2016. Formation of haloacetonitriles, haloacetamides, and nitrogenous heterocyclic byproducts by chloramination of phenolic compounds. Environ. Sci. Technol. 51, 665-663.

Parsons, S.A., Goslan, E.H., 2009. Evaluation of haloacetic acids concentrations in treated drinking waters (Project No.WT1236). London, UK.

Plewa, M.J., Muellner, M.G., Richardson, S.D., Fasano, F., Buettner, K.M., Woo, Y.-T., McKague, B.A., Wagner, E.D., 2008. Occurrence, synthesis, and mammalian cell cytotoxicity and genotoxicity of haloacetamides: an emerging class of nitrogenous drinking water disinfection byproducts. Environ. Sci. Technol. 42, 955-961.

Reckhow, D.A., MacNeill, A.L., Platt, T.L., MacNeill, A.L., McClellan, J.N., 2001. Formation and degradation of dichloroacetonitrile in drinking waters. J. Water Supply Res. Technol. - AQUA 50, 1-13.

Reckhow, D.A., Singer, P.C., Malcolm, R.L., 1990. Chlorination of humic materials: byproduct formation and chemical interpretations. Environ. Sci. Technol. 24, 1655-1664.

Richardson, S.D., Plewa, M.J., Wagner, E.D., Schoeny, R., DeMarini, D.M., 2007. Occurrence, genotoxicity, and carcinogenicity of regulated and emerging disinfection by-products in drinking water: A review and roadmap for research. Mutat. Res. - Rev. Mutat. Res. 636, 178-242.

Rook, J., 1974. Formation of haloforms during chlorination of natural waters. Water Treat. Exam. 23, 234-243.

Schreck, J.O., 1968. The Hofmann Amide Rearrangement. J. Chem. Educ. 45, 670-671.

Stevens, A.A., Moore, L.A., Miltner, R.J., 1989. Formation and control of non-trihalomethane disinfection by-products. J. Am. Water Work. Assoc. 81, 54-60.

Świetlik, J., Dąbrowska, M., Raczyk-Stanisławiak, U., Nawrocki, J., 2004. Reactivity of natural organic matter fractions with chlorine dioxide and ozone. Water Res. 38, 547-558.

Symons, J.M., Krasner, S.W., Simms, L.A., Sclimenti, M., 1993. Measurement of THM and precursor concentrations revisited: the effect of bromide ion. J. Am. Water Work. Assoc. 85, 51-62.

Templeton, M.R., Kanda, R., Graham, N., Kamal, H.M., Bond, T., 2012. Monitoring of nitrogenated DBPs in drinking water. Dep. Environ. Food Rural Aff. DWI 70/2/2, 90.

Wang, A., Lin, Y., Xu, B., Hu, C., Zhang, M., Xia, S., Zhang, T., Chu, W., Gao, N., 2018. Degradation of acrylamide during chlorination as a precursor of haloacetonitriles and haloacetamides. Sci. Total Environ. 615, 38-46.

Weinberg, H.S., Krasner, S.W., Richardson, S.D., Thruston, J.A.D., 2002. The Occurrence of Disinfection By-Products (DBPs) of Health Concern in Drinking Water: Results of a Nationwide DBP Occurrence Study. US Environmental Protection Agency.

WHO, 2011. Pharmaceuticals in Drinking-water. World Health 50, 600-3.

WHO, 2004. Acrylamide in Drinking-water Background document for development of WHO Guidelines for Drinking-water Quality 21.

Yu, Y., Reckhow, D.A., 2017. Formation and Occurrence of N-Chloro -2,2-dichloroacetamide, a Previously Overlooked Nitrogenous Disinfection Byproduct in Chlorinated Drinking Waters. Environ. Sci. Technol. 51, 1488-1497.

Zhang, Z., Zhu, Q., Huang, C., Yang, M., Li, J., Chen, Y., Yang, B., Zhao, X., 2020. Comparative cytotoxicity of halogenated aromatic DBPs and implications of the corresponding developed QSAR model to toxicity mechanisms of those DBPs: Binding interactions between aromatic DBPs and catalase play an important role. Water Res. 170, 115283.

Zhou, H., Xie, Y.F., 2002. Using BAC for HAA removal - Part 1: Batch Study. Am. Water Work. Assoc. 94, 194-200. 